\title{
West Circassian polysynthesis at the morphology-syntax interface
}

\author{
Ksenia Ershova*
}

\begin{abstract}
This paper presents an analysis of word formation in West Circassian, a polysynthetic language. I argue that while verbs and nouns superficially share a similar morphological profile, they are in fact constructed through two distinct word formation strategies: while verbal morphology is concatenated via syntactic head movement, the noun phrase is pronounced as a single word due to rules of syntax-toprosody mapping. Such a division of labor provides an account for why only nouns, and not verbs, exhibit productive noun incorporation in the language: West Circassian noun incorporation is prosodic, rather than syntactic. The evidence for this twofold approach to word formation comes from morpheme ordering in nominalizations.
\end{abstract}

Keywords. morphology-syntax interface; noun incorporation; polysynthesis; word formation; head movement; syntax to prosody mapping; West Circassian

1. Introduction. West Circassian, also known as Adyghe, of the Northwest Caucasian family displays complex polysynthetic morphology in both the verbal and nominal domains. Nouns and verbs share a similar morphological profile: both syntactic categories are constructed in accordance with the same morphological template. Despite these similarities, there is a puzzling difference between nouns and verbs in West Circassian: only nouns exhibit productive incorporation of lexical modifiers and dependents. I argue that this difference is due to the fact that nouns and verbs are in fact constructed via two distinct structural avenues: the verbal root and any verbal morphology that is present undergo head movement to form a complex head, while the noun and any accompanying nominal morphology are pronounced as a single phonological word due to a constraint on syntax-to-prosody mapping: the DP phase is mapped to a single phonological word. Incorporation of modifiers and dependents is then only available in the nominal domain because it is in fact not a syntactic process, but a consequence of this phase-to-word mapping rule.

Evidence for these two mechanisms of word formation comes from the morphology of verbal nominalizations. If a verb is nominalized, it may, like a regular noun, display incorporation of its verbal arguments. However, while in nonderived nominals incorporated lexical stems appear adjacent to the incorporating root (1), if the nominalized predicate has any verbal functional prefixes, those must appear between the verbal root and the incorporated argument (2).

(1) Position of incorporees in a nonderived nominal:

PREFIXES - Incorporee(s) - Root - SUfFIXES

(2) Position of incorporees in a nominalization:

*The data for this paper was collected in the village Neshukay (Bzhedug dialect $=\mathrm{Bz}$ ) and the Khatazhukay rural settlement (Temirgoy dialect $=\mathrm{Tg}$ ) of the Republic of Adygea, Russia. The author thanks the speakers of West Circassian for sharing their language, especially Svetlana K. Alishaeva and Susana K. Khatkova. The author is also grateful to Karlos Arregi, the participants of the Morphology \& Syntax Workshop at UChicago, and the audience at LSA92 for discussion and useful feedback. Special thanks goes to Yury Lander for continuous support in both the logistical and scientific aspects of this project. This project was partially funded by the Dissertation Research Grant from the Association for Slavic, East European, and Eurasian Studies. All mistakes and shortcomings are solely mine. Author's affiliation: University of Chicago (kershova@uchicago.edu).

Unconventional glosses: DIR - directive; DYN - PRS on dynamic verbs; MOD - modal future; PR - possessor. 
Incorporee(s) - PREFIXES verbal $_{\text {Root }}$ - SUFFIXES

I argue that the position of the verbal prefixes between an incorporated argument and the verbal root is a consequence of head movement: while the incorporated nominal remains in situ in the nominalized $v \mathrm{P}$, the verbal root undergoes head movement to form a complex head with the verbal functional projections above it.

The rest of the paper is organized as follows. Section 2 presents a brief overview of West Circassian morphosyntax, focusing in particular on nouns and verbs. Section 3 outlines the analysis. Section 4 focuses on the data from verbal nominalizations. Section 5 concludes.

2. Background on West Circassian morphosyntax. West Circassian is generally classified as polysynthetic, with prevalent head marking and complex agglutinative morphology (Smeets 1984:68-71; Arkadiev et al. 2009:18; Korotkova \& Lander 2010; Lander \& Letuchiy 2010; Lander 2015, inter alia). Thus, a typical verbal form includes prefixes referring to all of its arguments, as well as a range of morphology expressing voice, polarity, TAM, etc. For example, the verb in (3) carries prefixes marking four participants: from right to left, an ergative agent, a dative applied object, a benefactive applied object, and an absolutive theme. Additionally, this verb includes a causative prefix, a directive prefix, which generally marks directionality towards an interlocutor, and the past tense suffix.

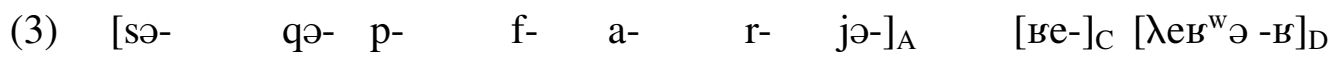

1SG.ABS- DIR- 2SG.IO- BEN- 3PL.IO- DAT- 3SG.ERG- CAUS- See -PST

'He showed me to them for your sake.' (Korotkova \& Lander 2010:301)

A nominal wordform, often referred to as the nominal complex, can likewise be morphologically complex and often includes several incorporated lexical roots, as well as functional morphology such as case, number, and possessive marking. ${ }^{1}$ For example, the nominal complex in (4) includes an incorporated nominal root $B^{W} ә n е \boldsymbol{B}^{W} \partial$ 'neighbor', a cross-reference marker referring to the possessor, which, in this case, is followed by the prefix jo- marking alienable possession, as well a number of suffixes marking plural number, absolutive case, and the additive coordinator $-j$.

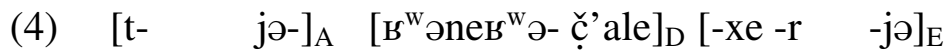

1SG.PR- POSS- neighbor- boy -PL -ABS -ADD

'and our neighbor boys' (Tg)

The morphemes in the above examples are grouped into zones based on the morphological template shown in Table 1.

As can be seen from the examples, this template is shared by both nominal and verbal wordforms. There is, however, an important difference between nominal and verbal stems: while nominals exhibit productive incorporation of lexical stems expressing various types of modifiers, noun incorporation is not observed in the verbal domain. An example of incorporation in the nominal domain can be seen in (4), where the root $B^{W}$ วne $B^{W} \partial$ 'neighbor' is incorporated into the head root $\check{c}$ 'ale 'boy'. This contrast between nominal and verbal stems most starkly manifests itself with verbal nominalizations. Like non-derived nominal stems, nominalizations may incorporate the arguments of the verb they are derived from. Thus, the nominalized form of the verb

\footnotetext{
${ }^{1}$ For a detailed description of the properties of the nominal complex, see Lander (2017).
} 


\begin{tabular}{|c|c|c|c|c|c|}
\hline $\begin{array}{c}\text { Argument } \\
\text { structure zone }\end{array}$ & $\begin{array}{c}\text { Pre-stem } \\
\text { zone }\end{array}$ & $\begin{array}{c}\text { Causative } \\
\text { marker(s) }\end{array}$ & \multicolumn{2}{|c|}{ Stem } & Endings \\
\hline (A) & (B) & (C) & \multicolumn{2}{|c|}{ (D) } & $(\mathrm{E})$ \\
\hline $\begin{array}{c}\text { Verbs: ABS, } \\
\text { ERG, IO } \\
\text { Nouns: POSS }\end{array}$ & $\begin{array}{c}\text { NEG, DYN, } \\
\text { jussive }\end{array}$ & CAUS & $\begin{array}{c}\text { incorporated } \\
\text { stems + root }\end{array}$ & $\begin{array}{c}\text { TAM-related } \\
\text { suffixes }\end{array}$ & $\begin{array}{c}\text { number, } \\
\text { case, etc. }\end{array}$ \\
\hline
\end{tabular}

Table 1: Morphological template (adapted from Lander 2017:79)

thač' the fact that these two roots form a single stem is evident from the appearance of possessive morphology to the left of both roots, as well as the lack of a stem edge vowel alternation - to be discussed below - in the incorporated root. When the same verb is used in a finite context, however, the theme may not be incorporated into the verbal stem in the same fashion (5b); instead, it must be expressed as a separate word $(5 \mathrm{c})$.

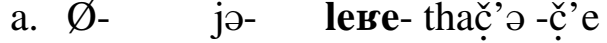
3SG.PR- POSS- dish- wash -NML
'his/her dish-washing'
b. * $\quad$ sə/s- leвe- thaç̌’ -в
1SG.ABS/ERG- dish- wash -PST

Expected: 'I washed dishes' c. lase-xe-r $\emptyset$-s-thač́’ə-ве

dish-PL-ABS 3ABS-1 SG.ERG-wash-PST

'I washed dishes.' (Tg)

There are two primary diagnostics for testing whether a lexical root is incorporated: (i) the position of the incorporated root within the full nominal complex and (ii) a vowel alternation that targets the last two syllables of the stem, i.e. zone D in Table 1 (Lander 2017:84-86). In terms of position within the wordform, any lexical material included in the nominal complex appears within zone D (the stem), with prefixes modifying the full nominal complex appearing to the left, and suffixes appearing to the right of the lexical material. The stem-edge vowel alternation is defined as follows: ${ }^{2}$ :

(6) If the two final syllables immediately preceding the right border of the stem both contain the vowel /e/ in its underlying form, the penultimate vowel is changed into /a/ unless it is a part of the pre-stem zone. (Lander 2017:80)

This alternation can be seen in action in examples (5a) and (5c). The root with the underlying form lе ве 'dish' surfaces faithfully in the former case, where it is incorporated into a larger stem and thus does not appear at the edge of zone D. In the latter case, on the other hand, this root appears as an independent phonological word and thus displays this alternation in the penultimate syllable.

The following section presents an analysis of word formation in West Circassian which accounts for the unavailability of noun incorporation in the verbal domain: the nominal complex is spelled out as a single word due to rules of syntax-to-prosody mapping, while the verbal form is constructed via head movement.

\footnotetext{
${ }^{2}$ See also Smeets (1984:206-211) and Arkadiev \& Testelets (2009:122-131).
} 
3. Analysis: Two strategies of word formation. This section outlines the core theoretical proposal of the paper. The claim is that words in West Circassian are derived via two distinct avenues based on whether they are contained within the extended projection of a nominal, or a verb. Verbal forms are constructed via head movement, while a nominal phrase is pronounced as a single word due to rules of phase-to-word mapping: a DP is spelled out as a single phonological word.

3.1. Head Movement. In this subsection I propose that the functional heads of the verbal extended projection are concatenated with the lexical verb via head movement to the highest head within the verbal extended projection.

Setting aside the argument structure zone, ${ }^{3}$ verbal morphology is organized in accordance with syntactic scope (see e.g. Korotkova \& Lander 2010 on scopal interactions in the suffixal domain). Thus, verbal prefixes are ordered as in (7); this is illustrated with the verbal form in (8).

(7) Tense / Low negation ${ }^{4}$ - Causative - Lexical verb

$$
\begin{aligned}
& \text { s- jo- mo- ве- } \check{\mathbf{s}}^{\prime} \mathbf{x} \text {-ew } \\
& \text { 1SG.ABS- 3SG.ERG- NEG- CAUS- laugh -ADV }
\end{aligned}
$$

'without her/him making me laugh (lit. while s/he is not making me laugh)' (Tg)

The above ordering can be mapped to a relatively uncontrovertial syntactic confuration, wherein negation scopes over the causative. The tree for (8) is presented in (9): the proper order of verbal affixes is derived via merging in accordance with syntactic scope and subsequent head movement of the verbal projections to $\mathrm{C}^{0}$, with the participating functional heads specified as prefixes or suffixes in regards to linearization. ${ }^{5}$

To summarize this subsection, verbal forms are derived via head movement. This is easily accounted for given the way affix ordering corresponds with assumptions about syntactic scope.

3.2. PHASE TO WORD MAPPING. While the verbal projection is assembled via head movement, the morphology that surfaces within the nominal complex is not adjoined to the nominal head via any syntactic operation, but rather is pronounced as a single unit due to rules of prosodification: the DP phase is mapped to a single phonological word.

\footnotetext{
${ }^{3}$ For the purposes of this paper, I assume that the argument structure zone is built via head movement like any other verbal functional morphology. There are, however, several complications to this approach, the discussion of which is outside the scope of the present paper. One complication is that the order in which cross-reference morphology appears does not directly correlate with syntactic scope; for example, the absolutive argument is always cross-referenced by the leftmost personal prefix, regardless of its status as internal or external argument.

${ }^{4}$ Prefixal tense morphology and negation do not cooccur; for details regarding the distribution of these markers see (Arkadiev et al. 2009:45).

${ }^{5}$ The low syntactic position of prefixal negation (under $\mathrm{T}^{0}$ ) correlates with it having narrow semantic scope; it constrasts with suffixal negation, which surfaces on the right edge of the verbal form and takes scope over the full assertion (Lander \& Sumbatova 2007).
} 


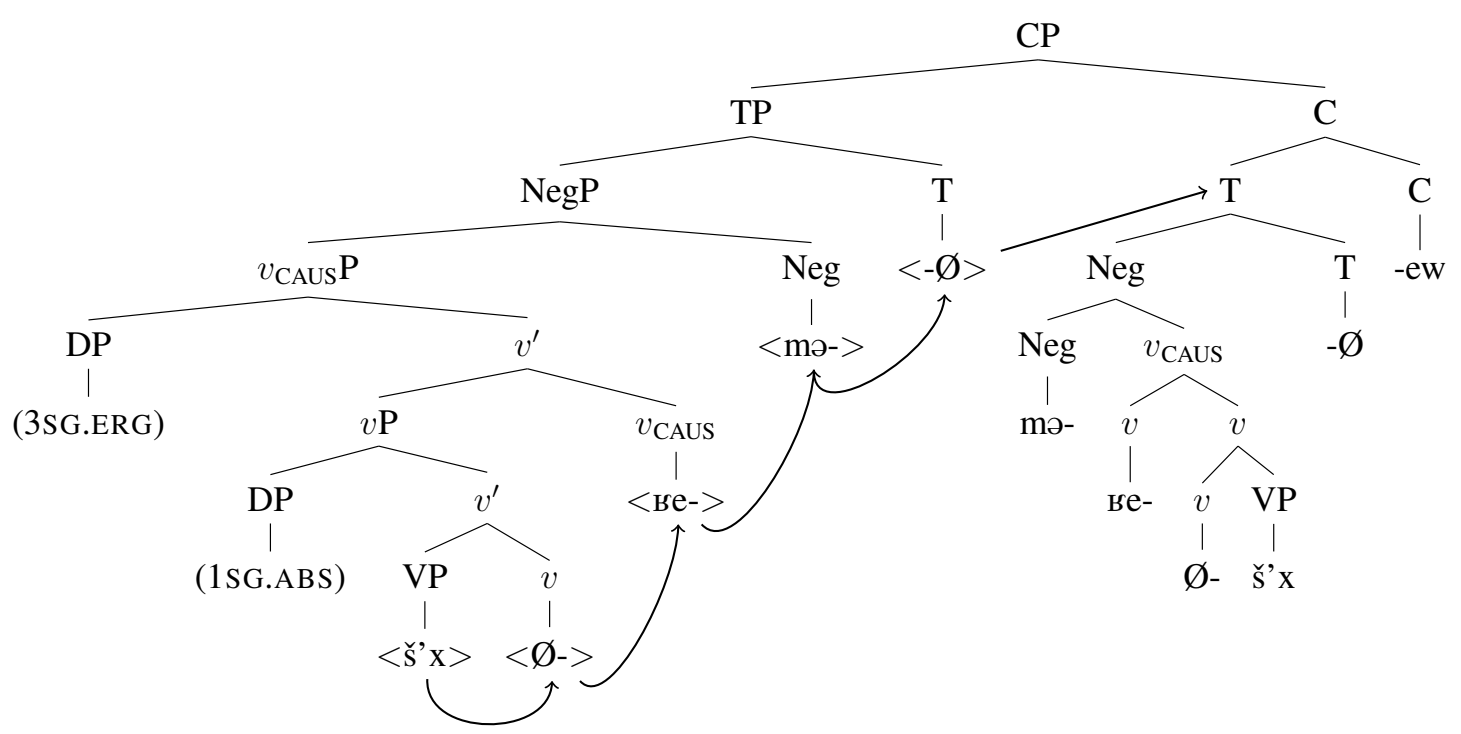

For example, the nominal complex in (4), repeated below in (10a), is derived in the following way: the nominal modifier $B^{\mathrm{W}} ә \boldsymbol{} \boldsymbol{B}^{\mathrm{W}} \partial$ 'neighbor' is merged as a caseless NP adjunct to the head noun čcale 'boy' and remains in situ in its base position throughout the derivation. Once $\mathrm{D}^{0}$ (the possessive prefix) is merged, its complement - NumP - is sent to spell-out, resulting in a single phonological word. The possessive prefix, case marker and additive particle attach postsyntactically as clitics via Morphological Merger (Marantz 1988 and subsequent work).

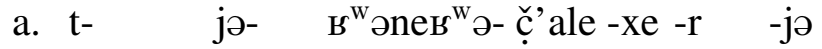

1SG.PR- POSS- neighbor- boy -PL -ABS -ADD

'and our neighbor boys' (Tg)

b.

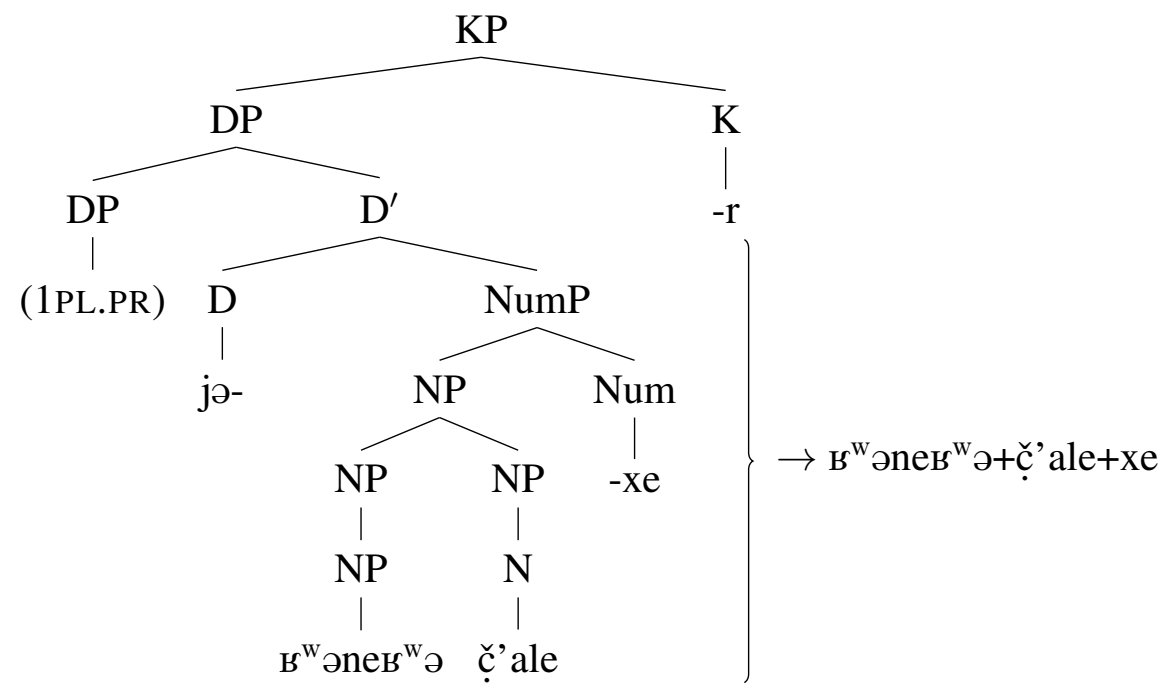

This analysis is based on the proposal set forth by Compton \& Pittman (2010), who argue that languages with morphologically complex words and productive noun incorporation differ from nonpolysynthetic languages in rules of mapping from syntax to PF. In particular, if we are to assume a form of Match Theory (Selkirk 2011) as a way of mapping from syntax to PF, then a polysynthetic language differs from a synthetic or isolating language in the following way. 
In the latter type of language a syntactic word - roughly speaking, a single syntactic node - is mapped to a phonological word, and a syntactic phrase is correspondingly mapped to a phonological phrase. In polysynthetic languages, on the other hand, syntactic phrases of a particular type may be mapped to a single phonological word, rather than to a prosodically more complex unit such as a phonological phrase.

Building on the assumption that the boundaries of syntactic phases are derivational points at which structure is sent to spell-out, Compton \& Pittman (2010) propose that the DP and CP phases in a number of polysynthetic languages are directly mapped to prosodic words. If phrased in terms of Optimality Theory constraints, polysynthetic languages differ from other types of languages in that they are subject to an additional constraint on syntax-to-prosody mapping: in addition to the three standard constraints of Match Theory (11), these languages are subject to a constraint that maps syntactic phases to prosodic words (12).

(11) Classic Match Theory constraints (Selkirk 2011:439):

a. MATCH ClAUSE: A clause in syntactic constituent structure must be matched by a corresponding prosodic constituent $[. .$.$] in phonological representation.$

b. MATCH PHRASE: A phrase in syntactic constituent structure must be matched by a corresponding prosodic constituent [...] in phonological representation.

c. MATCH WORD: A word in syntactic constituent structure must be matched by a corresponding prosodic constituent $[. .$.$] in phonological representation.$

(12) MATCH PHASE-TO-WORD: A phase in syntactic constituent structure must be matched by a prosodic word in phonological representation.

I propose that West Circassian is subject to a relativized version of the Match phase-toword constraint, in particular, DP phases (but not CPs) in West Circassian are directly mapped to a single prosodic word. Productive noun incorporation in the nominal domain is then a consequence of this mapping rule: the full nominal phrase, including any nominal or adjectival modifiers, must be pronounced as a single phonological word. Due to the fact that the CP phase, unlike the DP, is mapped to a phonological phrase, rather than a single word, verbs then do not exhibit this type of incorporation of dependent noun phrases.

What appears to be nominal or adjectival incorporation in West Circassian is then in fact a case of pseudo noun incorporation in Massam's (2001) sense: it is simply the phonological outcome of a nominal or adjectival phrase appearing within a particular structural domain with the head it modifies - it need not be the result of head or phrasal movement.

Building on similar argumentation by Barrie \& Mathieu's (2016) for Onondaga and Ojibwe, I provide below evidence that the incorporation of lexical material in West Circassian cannot be derived via head movement, as has been proposed for other cases of noun incorporation by (Baker 1988).

There are several difficulties for a head movement account of lexical incorporation in West Circassian nominal phrases. Firstly, the incorporated material can be morphologically complex and may include its own functional morphology between two lexical roots, thus violating Baker's (2003) Proper Head Movement Generalization:

(13) The Proper Head Movement Generalization (PHMG) (Baker 2003:53) A lexical head A cannot move to a functional head B and then to a lexical head $\mathrm{C}$. 
For example, a nominalized verbal form may be incorporated, with an overt nominalizer (-pipe) surfacing between the incorporated lexical root and the root hosting the incorporated element (14). In order to derive the word in (14) via head movement, the verbal root ̌̌ $e$ 'read' would need to undergo head movement to the nominalizing projection -pe, with the complex head subsequently moving to the nominal lexical root avtobus 'bus'. This type of movement (root $\rightarrow$ suffix $\rightarrow$ root) is a violation of the PHMG.

ja- $\quad$ [je-že-ṗe]- avtobus
3PL.PR+POSS- DAT-read-NML- bus
'their school bus' 6

A prosodification account, on the other hand, does not invoke any violations of this sort: the nominalized verbal form is incorporated into the full DP due to the fact that it is a caseless NP that is contained within a larger DP.

Secondly, a direct, and desired, prediction of a head movement account of noun incorporation is that it is restricted to the theme or direct object of the incorporation host (Baker 2009:154). West Circassian incorporation is not subject to such a restriction. Attributive modifiers, adjectival or nominal, are productively incorporated into the nominal they modify - for most types of nominal modifiers, incorporation is the only available strategy. For example, the wordform in (15) includes the nominal modifier šolk 'silk' and the adjectival modifier daxe 'pretty'.

(15) Ø- jə- Zə- šolk- ̌̌ene-daxe -r

3SG.PR- POSS- one- silk- dress- pretty -ABS

'one beautiful dress of hers' (Tg; Lander 2017:84)

Finally, deverbal nominalizations exhibit incorporation of the verbal arguments (to be discussed in detail in section 4); in such cases, incorporation is not limited to the theme or direct object of the nominalized verb. Thus, even an external argument may be incorporated into a verbal nominalization: if a transitive verb like thač'ว 'wash' (16a) is nominalized, both the theme and the agent may be incorporated into the nominalized form (16b).

a. mə pŝâse-m(ERG) lase-Xe-r(ABS) Ø-j-e-thaç̌’ə this girl-OBL dish-PL-ABS 3ABS-3SG.ERG-DYN-wash

'This girl is washing the dishes.'

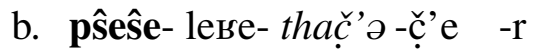

girl- dish- wash -NML -ABS

'girls' dish-washing' (Tg)

While it is not clear how a head movement analysis would derive the incorporation of the external argument in (16b), a prosodification account can be applied straightforwardly: in such a construction, both the internal and external argument are caseless NPs that remain in situ in their base-generated positions (17).

\footnotetext{
${ }^{6} \mathrm{http}: / / w w w . a d y g v o i c e . r u /$
} 


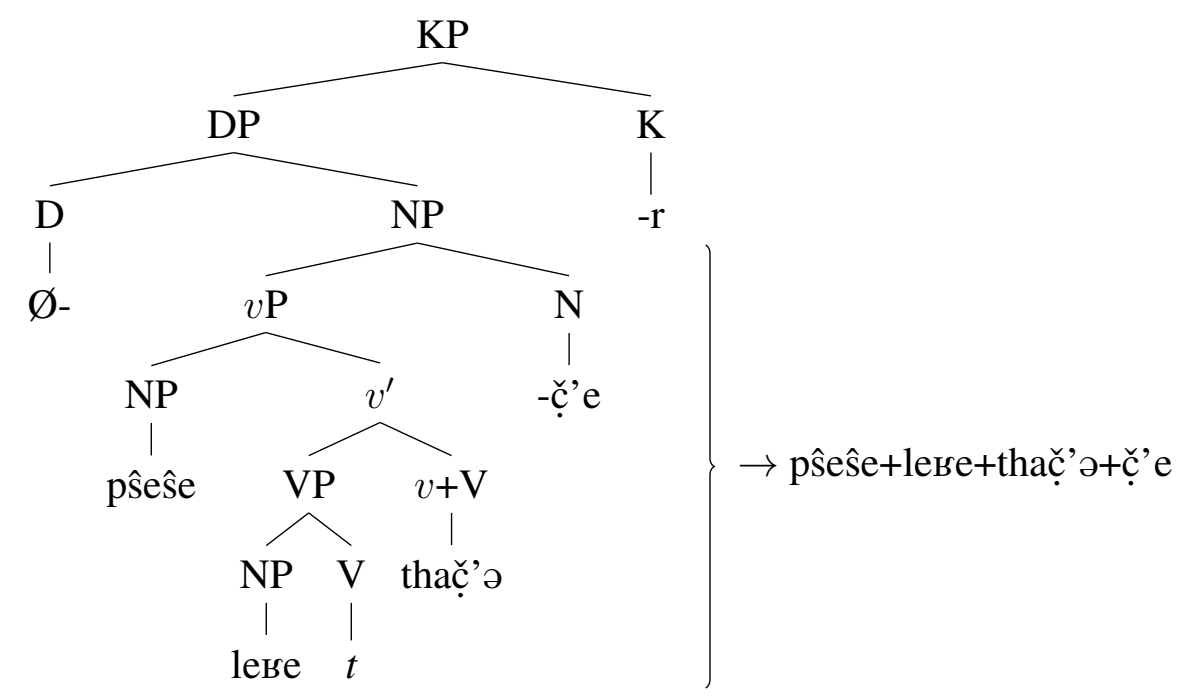

Thus, a head movement analysis cannot be easily applied to the West Circassian incorporation data. A prosodification account, on the other hand, readily predicts the observed structural configurations.

The following section presents evidence from the morphosyntax of verbal nominalizations for the necessity of both types of word formation strategies: prosodification in the nominal domain and head movement in the verbal domain.

4. Deriving nominalizations. In the previous section I have proposed two distinct word formation strategies for the West Circassian wordform: head movement in the verbal domain and rules of syntax-to-prosody mapping in the nominal domain. This section presents a case where both strategies are necessary in order to account for the observed morpheme order - noun incorporation in verbal nominalizations.

Like non-derived nominals, verbal nominalizations display argument incorporation, but the incorporated lexical material must appear to the left of any verbal functional morphology, thus violating the West Circassian morphological template, according to which incorporated lexical material appears next to the incorporating root. I argue that the observed morpheme order may only be derived via head movement of the verbal morphology, resulting in concatenation of the verbal form to the exclusion of the incorporated argument, while the incorporated argument remains stranded in its base position.

The assumption that the incorporated argument remains in its base position stems out of the impossibility of deriving noun incorporation via head movement, as has been shown in subsection 3.2, and is supported by two additional pieces of evidence: (i) the syntactic presence of the external argument within the nominalized construction, which then would serve as an intervener for movement-derived incorporation of the internal argument; and (ii) the Incorporation Hierarchy, which governs the order in which arguments may surface within a deverbal nominalization this hierarchy directly follows the underlying argument structure of the corresponding predicate.

The proposed analysis then provides an account for why noun incorporation is unavailable in the verbal complex - verbs are constructed in the syntax via head movement, but noun incorporation is phonological and licensed only within a DP projection, given the DP-phase-to-word match constraint. 
4.1. THE FUNCTIONAL STRUCTURE OF NOMINALIZATIONS. This paper focuses on three types of nominalized constructions: (i) the action nominal marked with the suffix $-n(\partial)$ (18a), (ii) the manner nominal marked with the suffix $-\breve{c}^{\prime} e(18 \mathrm{~b})$, and (iii) the place nominal marked with the suffix - $\dot{p} e$ (18c). All three suffixes can be productively combined with verbal stems, yielding a construction that exhibits the syntactic behavior typical of a noun phrase.
a. pŝâ̂e-m Ø- jə- leве-thač̣’ -n $\operatorname{səg}^{\mathrm{w}}$ rjehə
girl-OBL 3SG.PR- POSS- dish- wash -NML I like
'I like the girl's dish-washing.'

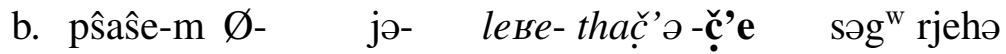 girl-OBL 3SG.PR- POSS- dish- wash -NML I like
'I like the girl's manner of dish-washing.'

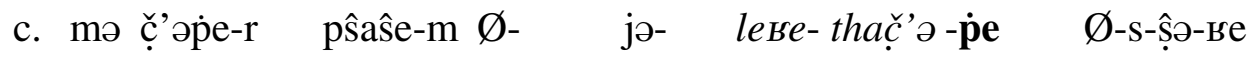 this place-ABS girl-OBL 3SG.PR- POSS- dish- wash -NML 3ABS-1SG.ERG-do-PST 'I made this place the girl's place for dish-washing.' (Tg)

I argue that these three nominalizers all select for a projection which includes the full $v \mathrm{P}$, but crucially excludes $\mathrm{T}^{0}$, which is responsible for licensing absolutive and ergative case assignment. I further show that the nominalized verbal phrase includes the full argument structure of the predicate it is derived from. In particular, if a bivalent predicate is nominalized, both the internal and external arguments are syntactically present within the nominalized construction (19).

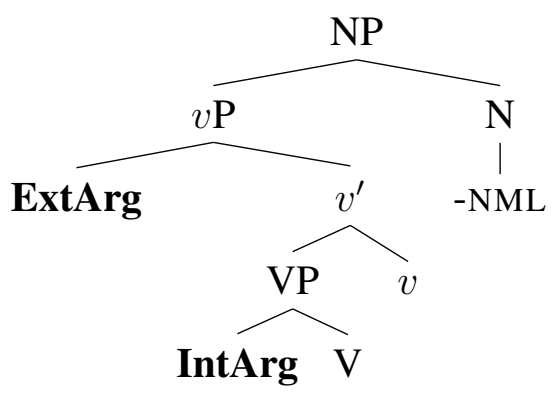

Nominalized structures differ drastically from other types of clausal embedding: while embedded clauses retain regular verbal agreement and case marking of participants, nominalizations do not display ergative or absolutive agreement, and cannot assign the corresponding cases to their arguments. Arguments which are not assigned case by the verb must either surface as an incorporated nominal, or as a possessor. Thus, in (20a) the embedded transitive predicate that is marked with a factive subordinating prefix ${ }^{7}$ displays agreement with the ergative and absolutive arguments, and assigns oblique and absolutive case to the corresponding nominals. On the other hand, if the same predicate undergoes nominalization with one of the prefixes listed above, it no longer displays overt verbal agreement with the arguments, and the corresponding nominals are not assigned oblique or absolutive case (20b). The arguments must instead be incorporated or licensed as a possessor of the newly formed nominal phrase (18a)-(18c).

\footnotetext{
${ }^{7}$ Embedded clauses marked with the factive prefix zer $(e)$ - are generally analyzed as a type of relative clause; see Gerasimov \& Lander (2008), Caponigro \& Polinsky (2011:103-111), Lander (2012:296-309) on the semantic and morphosyntactic properties of the factive prefix.
} 
a. [adre-me(ERG) lase-r(ABS) Ø-zer-a-thač̣’

other-PL.OBL dish-ABS 3ABS-FCT-3PL.ERG-wash-DYN-OBL
s-
$\mathrm{s} \partial \mathrm{g}^{\mathrm{W}}$ rjehə

1SG.ABS-3SG.IO-DAT-watch-MOD-ABS I like

'I like to watch other people wash dishes.' ( $\mathrm{Tg}$ )

b. * [pŝâse-m lase-xe-r thaç̌’ girl-OBL dish-PL-ABS wash-NML -ABS I like

Intended: 'I like the girl's washing of dishes.' (Tg)

The fact that absolutive and ergative case and cross-reference marking are unavailable in nominalizations suggests that the head that is responsible for the assignment of these case values and the licensing of cross-reference morphology is absent in these constructions. I propose that this head is $\mathrm{T}^{0}$ - this is corroborated by the fact that tense-related morphology may not be used on a nominalized predicate: attempts to attach the nominalizing suffix to a predicate marked with the future, modal future or past tense suffix renders an illicit wordform (21).

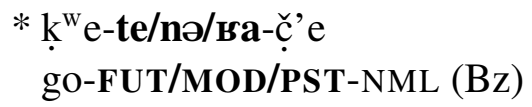

I assume that West Circassian is an ABS=NOM language in Legate's (2008) terms, meaning that absolutive case is uniformly assigned by $\mathrm{T}^{0}$ to both internal and eligible external arguments. This assumption is supported by the fact that the language does not display any of the properties associated with a case system wherein absolutive case can in fact be separated into two structural cases: nominative and accusative. Ergative case, on the other hand, is assigned as inherent case by $v^{0}$.

Absolutive case is then unavailable in nominalizations due to the absence of $\mathrm{T}^{0}$ in the relevant construction. In regards to ergative case I propose, following similar proposals for accusative case (Watanabe 1996; Kishimoto 2006), that $v^{0}$ may only assign ergative case in the presence of $\mathrm{T}^{0}$ (see also Legate 2008 on the dependence of inherent ergative case assignment in Hindi on the presence of perfective aspect).

Given that ergative case isn't assigned within the nominalized construction, one might suppose that the external argument is altogether absent from these nominalizations, and the possessor that we see in (18a)-(18c) is merely interpreted as the external argument, but is not introduced by $v^{0}$ (cf. Legate 2008:63 on Warlpiri). However, there is evidence that both the functional head that introduces the external argument and the external argument itself are structurally present in these constructions. Firstly, the nominalized predicate may contain an overt causative morpheme - a type of external argument introducing functional projection (22).

zarjəne $\varnothing-\quad$ jə- keše- $\quad$ se- $\quad \hat{z}^{\mathrm{w}} \mathrm{a}-$ ç̣’e $^{\prime}$

Zarina 3SG.PR- POSS- porridge- CAUS- boil -NML

'Zarina's way of making (lit. boiling) porridge' (Tg)

Secondly, there is evidence that the external argument is syntactically present in these constructions, either as an incorporated noun phrase, a possessor, or a non-obligatory control PRO. The evidence comes from the following diagnostics: 
1. The ability of the external argument to bind anaphors within the $v \mathrm{P}$. An example of this is provided below: in (23) we can see a reciprocal prefix referring to the comitative applied object being used in a nominalization without an overt external argument. Since reciprocals semantically require a plural antecedent and the subject of the matrix clause is singular, we must assume that there a PRO binding the reciprocal within the nominalization.

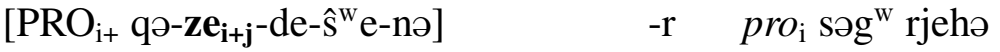

$$
\begin{aligned}
& \text { DIR-REC.IO-COM-dance-NML -ABS I like }
\end{aligned}
$$

2. The ability of the external argument to be modified by the adverbial intensifier jež'jež'rew or to control a depictive secondary predicate. For example, the nominalized construction in (24) includes this intensifier, which is controlled by the external argument of the nominalized verb, expressed here as a possessor.

$$
\begin{aligned}
& \text { jež'jež'rew pŝâ̂e-m Ø-jə-leве-thaç̌’ə-с̣’'e } \quad \text { səg }{ }^{\mathrm{w}} \text { rjehə } \\
& \text { by.oneself girl-OBL } 3 \text { SG.PR-POSS-dish-wash-NML I like }
\end{aligned}
$$

'I like how the girl washes the dishes by herself.' (Tg)

This intensifier may only be controlled by the participant of a predication; thus, it cannot modify the possessor of a non-derived nominal, as in (25).

$$
\begin{aligned}
& \text { (*jež'jež'rew) mə pjəsatjeljə-m } \varnothing \text {-jə-txə } \lambda \quad \text { des }^{\mathrm{w}} \text {-ded } \\
& \text { by.oneself this writer-OBL 3SG.PR-POSS-book good-very }
\end{aligned}
$$

'This writer's book (*by herself) is very good.' (Tg)

Thus, the nominalized construction includes the full $v \mathrm{P}$. Other verbal functional material that may be included in the nominalization includes low scope prefixal negation mə- (26) and certain low aspectual or event modifiers.
w-jə-aqče-ja-mə-tə-č̣’e
hejnape-m nesə-s
2SG.PR-POSS-money-3PL.IO-NEG-give-NML
shame-OBL reach-PST

'Your unwillingness to give money (lit. your manner of not giving money to them) has become shameful.' (Bz)

Thus, the nominalized projection may be slightly larger than $v \mathrm{P}$ in order to include negation and aspectual functional material. Crucially, as we saw in (21), nominalizations may not include a tense projection, which correlates with the lack of absolutive and ergative case in these constructions.

In regards to the expression of the verbal arguments in the nominalized construction, there is a constraint on the order in which they appear - in particular, the internal argument must appear closer to the incorporating root than the external argument (Ershova 2015). For example, the incorporated arguments in (16b), repeated below in (27a), cannot surface in the reverse order, with the theme lese 'dish' preceding the agent $p \hat{s} e \hat{s} e$ 'girl' - in this case, the leftmost incporated nominal is necessarily interpreted as the agent, rendering a semantically odd interpretation. 
a. pŝeŝe- lеве- thač́’ -č́'e -r

girl- dish- wash -NML -ABS

'girls' dish-washing' b. \# leве- pŝeŝe- thač̆’ -ç'e -r

dish- girl- wash -NML -ABS

\# 'dishes' girl-washing'

*'girls' dish-washing' (Tg)

This constraint on the order of arguments is most easily accounted for within the general analysis of modifier incorporation in the nominal complex that was proposed in subsection 3.2: the arguments in (27a) remain as caseless NPs in situ within the nominalized $v \mathrm{P}$ and are pronounced as part of the nominalized word due to the DP phase-to-word mapping rule. Noun incorporation in verbal nominalizations is thus epiphenomenal to modifier incorporation in West Circassian nominals generally: it is the result of the same process of matching syntactic constituents with prosodic structures - in this case, the DP phase with the prosodic word.

4.2. MORPHEME ORDERING IN NOMINALIZATIONS. In the previous subsection, I argued that noun incorporation in verbal nominalizations is a consequence of the same process as incorporation of modifiers in non-derived nouns: the DP phase, including any modifiers or arguments that are within it, is spelled out as a single word. There is, however, an important difference between noun incorporation in verbal nominalizations and the same phenomenon in non-derived nouns. In particular, in the case of non-derived nouns, incorporated lexical material appears immediately adjacent to the incorporating root, while functional affixes appear farther away from the root (28). In nominalizations, on the other hand, while nominal functional prefixes appear as expected, to the left of the incorporated nominal, verbal functional material surfaces between the incorporated noun and the verbal root (29).

(28) Morpheme order in non-derived nouns:

PREFIXES - Incorporee(s) - Root - SUFFIXES

(29) Morpheme order in nominalizations:

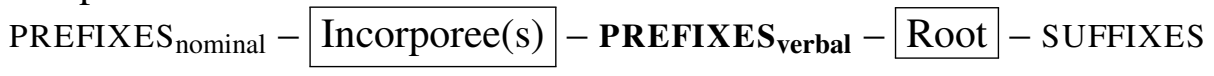

This contrast is shown in the examples below. In (30) the root adəre 'Adyghe' is incorporated into the nonderived nominal root bze 'tongue, language' (surfacing as adryabze due to the stem-edge phonological alternation). In this case, functional morphology such as the negative prefix mə- appears to the left of the incorporated nominal. In (31), on the other hand, the nominal lе ве 'dish' is incorporated into the nominalized verbal stem thač' $ə$ 'wash' - in this case, the same negative prefix mə- appears between the incorporated stem and the verbal root. Another example of verbal functional morphology appearing between an incorporated nominal and the nominalized verbal stem is presented in (32): here, the causative prefix ве- appears between the incorporated nominal keše 'porridge' and the verbal root $\hat{z}^{w} e$ 'boil'. Nominal functional prefixes, on the other hand, such as the possessive markers in (31) and (32), appear to the left of the incorporated nominal.

$$
\begin{aligned}
& \text { mo- adəуa- bze } \\
& \text { NEG- Adyghe- language } \\
& \text { 'not Adyghe language' }
\end{aligned}
$$


(31) wjə- leвe- mə- thaç’’ -č̣'e
2SG.POSS- dish- NEG- wash -NML

'your manner of not washing dishes' (Bz)
(32)

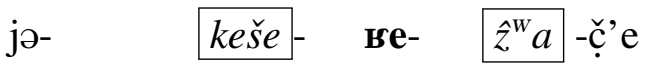

$$
\begin{aligned}
& \text { 3SG.POSS- porridge- CAUS- boil -NML } \\
& \text { 'his/her manner of porridge-cooking' (Tg) }
\end{aligned}
$$

In the previous section I have argued the incorporated arguments of a nominalized predicate remain in situ in their base generated positions. Thus, in both (31) and (32) the incorporated argument remains in its base generated position as the complement of the lexical verb. Such a structure, however, predicts that the incorporated nominal should appear adjacent to the head

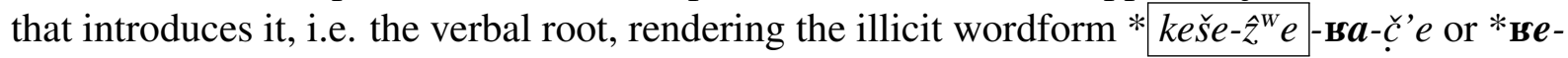
$k e \check{s} e-\hat{z}^{w} a-\check{c}^{\prime} e$. As can be seen in (32), this prediction is not borne out: the causative morpheme se- surfaces between the incorporated internal argument and the lexical verb that introduces it. The observed morpheme order is however easily derived if we assume that verbal projections are not spelled out in their base generated positions, but instead undergo head movement, as described in section 3.1. This is illustrated in (33): the lexical verb undergoes head movement to $v^{0}$,

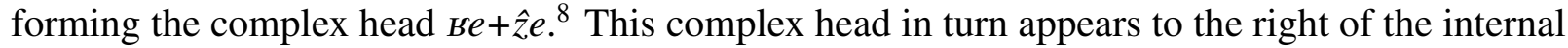
argument, which remains in situ as the complement of $\mathrm{V}^{0}$, thus arriving at the correct morpheme order.

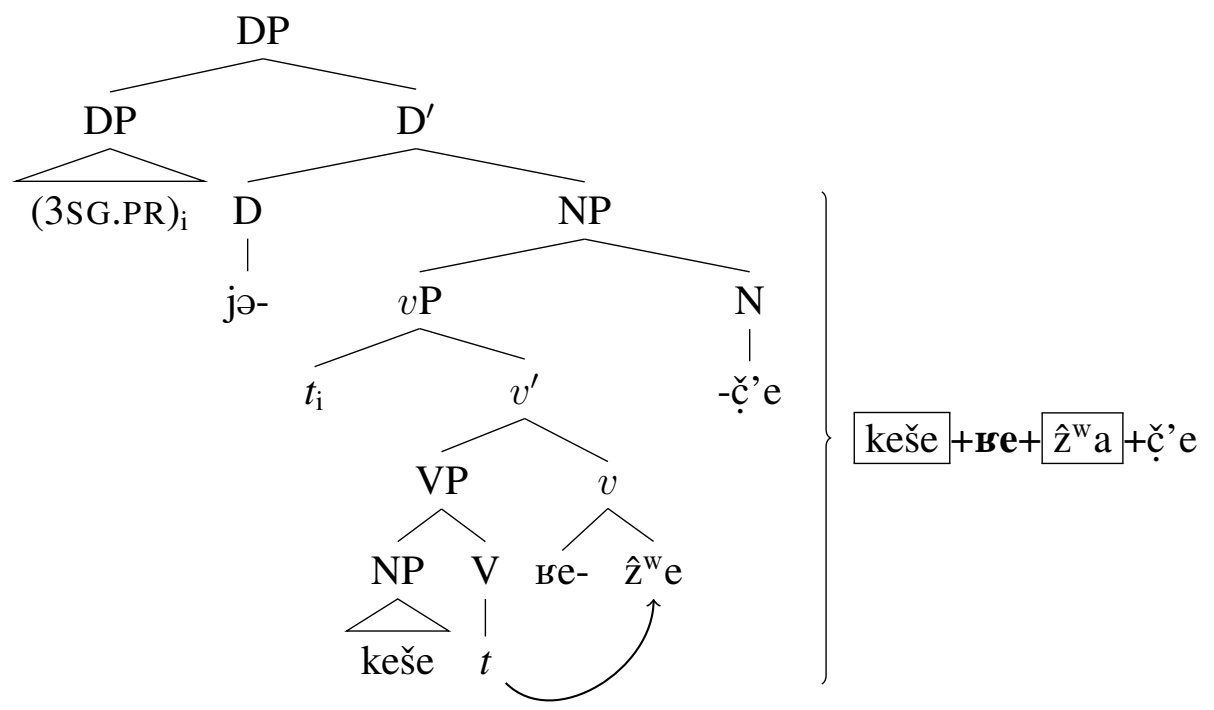

The morpheme order we see in (31) is derived in a similar fashion: the internal argument lе ве 'dish' remains in situ as the complement of $\mathrm{V}^{0}$, while the verbal root undergoes head movement to form a complex head with the negative prefix - this structure in shown in (34).

\footnotetext{
${ }^{8} \mathrm{I}$ assume that the external argument originates within the nominalized $v \mathrm{P}$, but, being a full DP, moves to the higher Spec,DP for case assignment.
} 


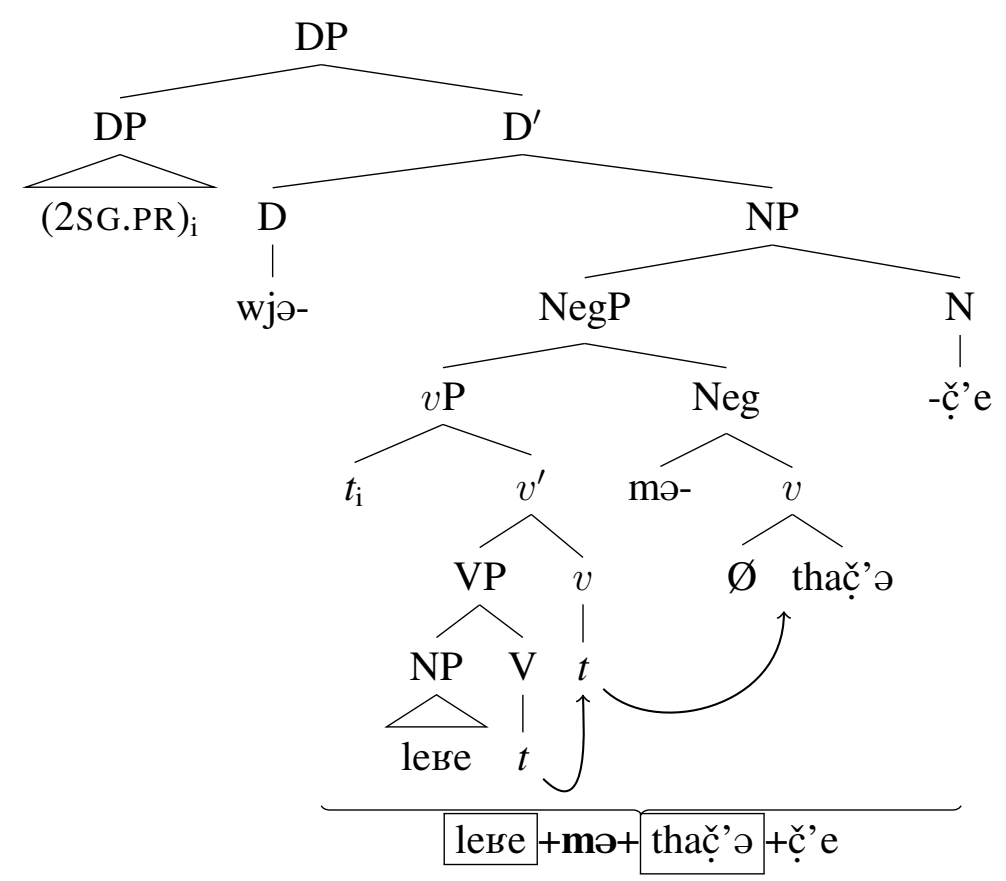

Thus, the unusual morpheme ordering observed in verbal nominalizations, wherein verbal functional morphology appears between the verbal root and the incorporated argument, arises through a combination of two word formation mechanisms: the incorporated nominal is pronounced as part of the nominalized verb due to phase-to-word mapping rules, while verbal functional morphology forms a complex head with the verbal root via head movement.

5. Conclusion. This paper provides an analysis of word formation in West Circassian. I have argued that words in the nominal and verbal domains are constructed via two distinct avenues: a nominal phrase is mapped to a single phonological word due to rules of syntax-to-prosody mapping, while verbal forms are constructed in the syntax via head movement. This difference in mechanisms of word formation accounts for productive incorporation of lexical modifiers in the nominal domain and the lack of noun incorporation in the verbal domain: incorporation of lexical material is not syntactic, but is in fact a consequence of the DP phase being mapped to a single phonological word. Since incorporation of this type is purely prosodic and limited to the DP phase, it is not expected to occur in the verbal domain, wherein words are built syntactically through head movement. Further evidence for the presence of two word formation strategies comes from morpheme ordering in verbal nominalizations.

\section{References}

Arkadiev, P.M., Yu.A. Lander, A.B. Letuchiy, N.R. Sumbatova \& Ya.G. Testelets. 2009. Vvedenije. Osnovnyje svedenija ob adygejskom jazyke [Introduction: Basic information on Adyghe]. In Ya. G. Testelets (ed.), Aspekty polisintetizma: Očerki po grammatike adygejskogo jazyka, 17-120. Moscow: RGGU.

Arkadiev, P.M. \& Ya.G. Testelets. 2009. O trex čeredovanijax v adygejskom jazyke [On three alternations in Adyghe]. In Ya. G. Testelets (ed.), Aspekty polisintetizma: Očerki po grammatike adygejskogo jazyka [Aspects of polysynthesis: Sketches on the grammar of Adyghe], 121-145. Moscow: RGGU. 
Baker, Mark. 1988. Incorporation. A Theory of Grammatical Function Changing. Chicago/London: University of Chicago Press.

Baker, Mark. 2009. Is head movement still needed for noun incorporation? Lingua 199. 148-165. https://doi.org/10.1016/j.lingua.2007.10.010.

Baker, Mark C. 2003. Lexical categories. Cambridge \& New York: Cambridge University Press. https://doi.org/10.1017/CBO9780511615047.

Barrie, Michael \& Eric Mathieu. 2016. Noun incorporation and phrasal movement. Natural Language \& Linguistic Theory 34. 1-51. https://doi.org/10.1007/s11049-015-9296-6.

Caponigro, Ivano \& Maria Polinsky. 2011. Relative embeddings: A Circassian puzzle for the syntax/ semantics interface. NLLT 29(1). 71-122. https://doi.org/10.1007/s11049-011-9121-9.

Compton, Richard \& Christine Pittman. 2010. Word-formation by phase in Inuit. Lingua 120. 2167-2192. https://doi.org/10.1016/j.lingua.2010.03.012.

Ershova, Ksenia. 2015. Non-canonical noun incorporation in Bzhedug Adyghe. Berkeley Linguistics Society (BLS) 41. 99-120. https://doi.org/10.20354/B4414110014.

Gerasimov, D.V. \& Y.A. Lander. 2008. Reljativizacija pod maskoj nominalizacii i faktivnyj argument $\mathrm{v}$ adygejskom jazyke [Relativization under the mask of nominalization and factive argument in the adyghe language]. In V.A. Plungian \& S.G. Tatevosov (eds.), Issledovanija po glavol'noj derivacii, 290-313. Jazyki slavjanskix kul'tur.

Kishimoto, Hideki. 2006. Japanese syntactic nominalization and VP-internal syntax. Lingua 116(6). 771-810. https://doi.org/10.1016/j.lingua.2005.03.005.

Korotkova, Natalia \& Yury Lander. 2010. Deriving affix ordering in polysynthesis: Evidence from Adyghe. Morphology 20. 299-319. https://doi.org/10.1007/s11525-010-9185-y.

Lander, Yury. 2012. Reljativizacija v polisinteti`ceskom jazyke: adygejskie otnositel'nye konstrukcii v tipologi ${ }^{`}$ ceskoj perspektive: RSUH dissertation.

Lander, Yury. 2015. Aktanty i sirkonstanty v morfologii i v sintaksise adygejskogo jazyka [Arguments and adjuncts in the morphology and syntax of Adyghe]. MJL 17.

Lander, Yury. 2017. Nominal complex in West Circassian: Between morphology and syntax. Studies in Language 41(1). 76-89. https://doi.org/10.1075/sl.41.1.03lan.

Lander, Yury \& Alexander Letuchiy. 2010. Kinds of recursion in Adyghe morphology. In Harry van der Hulst (ed.), Recursion and human language, 263-284. De Gruyter Mouton. https://doi.org/10.1515/9783110219258.263.

Lander, Yury \& Nina Sumbatova. 2007. Adygejskie otricanija [Adyghe negation]. In Kavkazskij lingvisti`ceskij sbornik, vol. 18, 77-103. Academia.

Legate, Julie Anne. 2008. Morphological and abstract case. Linguistic Inquiry 39(1). 55-101. https://doi.org/10.1162/ling.2008.39.1.55.

Marantz, Alec. 1988. Clitics, morphological merger, and the mapping to phonological structure. Theoretical morphology 253-270.

Massam, Diane. 2001. Pseudo noun incorporation in Niuean. NLLT 19(1). 153-197. https://doi.org/10.1023/A:1006465130442.

Selkirk, Elisabeth. 2011. The syntax-phonology interface. In John Goldsmith, Jason Riggle \& Alan Yu (eds.), The handbook of phonological theory, Wiley Blackwell 2nd edn. https://doi.org/10.1002/9781444343069.ch14.

Smeets, Henricus Joannes. 1984. Studies in West Circassian phonology and morphology. LINCOM Europa.

Watanabe, Akira. 1996. Case-absorption and wh-agreement. Dordrecht: Kluwer. 